\title{
Combating problems related to library software in higher education institutions of Pakistan: An analysis of focus groups
}

\author{
Nadeem Siddique and Khalid Mahmood \\ Gad \& Birgit Rausing Library, Lahore University of Management Sciences, \\ D. H. A., Lahore Cantt. 54792, Lahore, PAKISTAN \\ Department of Information Management, \\ University of the Punjab, Lahore, PAKISTAN \\ e-mail: nadeemsiddique@gmail.com (corresponding author); khalid.im@pu.edu.pk
}

\begin{abstract}
The absence of standard library software is one of the main hinderance in the effective automation of libraries of Higher Education Institutions (HEIs) of Pakistan. A review of the literature does not provide the actual requirements of the libraries in Pakistan related to library software and highlights the absence of library software selection criteria. This paper explores the opinion of the experts about the current status of library software, problems faced by the libraries and needs relevant to library software in order to suggest a sustainable solution for the automation of the libraries of HEls of Pakistan. This study was conducted using qualitative approach and three focus groups were conducted in Lahore, Islamabad and Karachi. The participants of all three focus groups comprised librarians from HEls, Library and Information Science (LIS) experts with experience in designing and implementing library software, LIS educators with experience of teaching library automation and computer science professionals having experience with library software. A purposive sampling was made in this regard. A discussion guide was prepared on the basis of literature review and expert opinions. Data were analyzed qualitatively. The analysis of focus groups revealed that there was a shortage of library software and the libraries of HEIs were still in the process of automation. Few libraries were using standard software but most of the libraries had implemented cataloguing module only. The non-availability of standard library software, regional languages, lack of awareness, lack of funds and lack of vision in the top management of HEls were the common problems causing hinderance in the effective automation of the libraries. The experts suggested formulation of a consortium under the umbrella of HEC that takes the resposibility of development and distribution of the software.
\end{abstract}

KEYWORDS: Library software; Integrated library system; Library automation; Academic libraries; Pakistan

\section{INTRODUCTION}

Information has become a fundamental concern for social, cultural and economic developments of any society in the world. Those who have timely access to the needed information and use it effectively are progressing rapidly. Information and Communication Technology (ICT) has changed the way of processing and disseminating information. The boom 
of ICTs has narrowed down the gap between invention and consumption of information. A rapid growth in ICTs has challenged library professionals and compelled them to redefine and restructure libraries and their services. Information technology has reduced the difference between physical collection and information available out of the library. It has provided the concept of "library without walls" and emerged an idea of virtual library where information is accessed remotely without visiting libraries hence revolutionized the information access. The concepts of ownership and library collection have been replaced with the concepts of access and connections respectively (Rubin 1998). It has also changed the information seeking behaviour of users and set new challenges for library professionals to enhance their skills and services to satisfy ever changing needs of library users (Amekuedee 2005; Wijayaratne 2005).

Despite new challenges, ICT is helping library professionals in disseminating required information to their patrons after repackaging and making it useful in an effective manner. The professionals are also using different software and electronic mail in their job functions. The technology has made resource sharing very easy that was not possible in the past (Misra and Phadke 1995). Libraries are using information technology for their processes to reduce unnecessary efforts and duplication of work. Libraries are getting benefit from online cataloging systems and doing copy cataloging that has reduced their cost and efforts in cataloging activities (George 2007). It has become impossible for libraries to ignore its use due to its benefits of handling a large amount of data effectively and efficiently. It has been used in almost all areas of library including acquisition, cataloging, classification, circulation and serials control. The services such as Selective Dissemination of Information (SDI) and Current Awareness Service (CAS) have been facilitated with the blessing of computers (Mahmood 1996).

Libraries are using different library software to automate their operations. Integrated library systems (ILS), like other technologies, are playing an essential role in facilitating libraries in running their operations more quickly and efficiently. An ILS has facilitated in the completion of all library traditional functions instantly and accurately. It has enabled libraries to eliminate backlogs, helped in efficient record maintenance and assisted in generating desired reports (Bills 2000). It has facilitated not only the academic libraries of all types but also helped large consortia of public libraries by combining different modules of the systems. It has not only supported library professionals but also assisted the library users by revolutionizing the library processes (Fayen 2010).

An ILS has experienced a lot of significant changes since its inception. The software starting from a simple database to store and retrieve library collection became an integrated library system that integrated all modules related to library processes and operations. Similarly, after arrival of the Internet, developments in information technologies, ever increasing number of electronic resources and growing expectations of users have caused further development in ILS. The ever changing needs of ILS have caused a great challenge for vendors and library professionals to work hard to meet new requirements of libraries (Kinner and Rigda 2009).

Although libraries are adopting ICTs to automate their routines but they still need to achieve more. The integrated library systems (ILS) are helping the automation of traditional collection but could not manage the electronic collection. The management of both print and electronic collection is still a challenge for ILS. Information technologies have helped in the enhancement of library services but they are also creating more challenges for library professionals and ILS 
vendors. Users are more ICT literate and they expect library search services to be better than Google and Amazon. They need a single interface to search the required information in any format not only from their computers but from mobile devices such as cell phones or PDAs. Therefore, library professionals and ILS vendors should adapt themselves according to the changes occurring in the world of information technologies. They need to be more usercentered and upgrade ILS according to current needs and ease of the users (Fayen 2010; Wang 2009).

\section{A REVIEW OF LIBRARY AUTOMATION IN PAKISTAN}

Libraries in Pakistan are considered as early adopters of computers in performing different library functions. The pioneer activities of library automation in Pakistan started with the creation of a data processing unit at PASTIC (Pakistan Scientific and Technological Information Center) in 1968. PASTIC helped to produce the country's first Union Catalog of Scientific Periodical and a profile of 100 scientists were developed to provide an SDI service. But a significant shift towards automation was seen in 1980s when a number of libraries were computerized. Although, librarians had fear about the use of computer in the beginning but some took the initiative and started using software mostly for cataloging and inventory purpose, whereas, only a few academic libraries were able to computerize circulation (Haider 1998; Ramzan and Singh 2009).

The library literature in Pakistan does not provide much information about the current status of library automation in the country. Some popular software that Pakistani libraries are using to automate their library routines include dBase, Foxpro, INMAGIC, CDS/ISIS, MINISIS, KITABDAR, Pak Library Software, and Library Automation and Management Program (LAMP). Kitabdar based on PASCAL language developed by Silicon System Ltd., which supports both Urdu and English languages, is considered as the first library software that facilitates Urdu language. It provides option of data entry in both English and Urdu languages in the same field. Although it has some good features, it does not have any standard format and designing of circulation module. Pak Book Corporation developed software for medium sized libraries but the software failed to meet the needs of the libraries and does not exist anymore (Mahmood 1996).

Some studies were conducted to reveal the status of library software used in different libraries of Pakistan (Ahmad 1993; Ansari and Zia 2010; Idrees 1995; Ramzan and Singh 2009; ShafiUllah 2009; Shafique and Mahmood 2008). These studies revealed that there is a variety in the library software development that are being used in the libraries of Pakistan. Most of them are in-house developed, off-the shelf imported software, locally developed software and free software. Some of the important software (in alphabetical order) are such as CDS/ISIS, INMAGIC, INMAGIC DBTEXT, KITABDAR, Koha, LAMP, LIB/SYS, LIBMS, LIBRA, Library Management System, Library World, LIMS, MLIMS, Sci-Mate, VTLS VIRTUA and WINISIS.

The available literature in library automation highlights problems that are causing hindrance in effective automation of libraries in Pakistan. Library automation requires ample financial resources in the acquisition of hardware and software. Pakistan is a developing country and faces financial issues. A very small budget is allocated every year to education, and libraries receive very small share in this way. Therefore, it is difficult for libraries to carry out 
automation activities due to its high cost. Libraries do not receive special grant to acquire hardware and software (Haider 1998; Mahmood 1996; Riaz 1993).

Along with the hardware, an integrated library system is required for automation of libraries as well. Numerous library software are available in the advanced countries and directories are available to help librarians for the selection of software but the situation is not same in Pakistan. The libraries in Pakistan are using software of different types; no standard software is locally available that provides complete solution to the libraries and foreign library software do not fullfil the local requirements. On the other hand, the available software are not affordable for libraries due to their price and maintenance cost. There is a lack of technical support and maintenance facility in Pakistan and libraries are using in-house developed software in most of the cases. There is a shortage of library software vendors and consultancy for the development of the software. Vendors are hesitant to provide services due to some reasons such as software piracy (Haider 1998; Idrees 1995; Mahmood 1996; Riaz 1993; Shafi-Ullah 2009).

Lack of coordination and working in isolation is also one of the big obstacle in effective library automation projects in the country. Libraries are working on automation projects in isolation without benchmarking others' experiences into account. There is a lack of coordination among libraries even those using the same software. Similarly, there is no coordination among departmental libraries of a univeristy and each library is using different software matching with its requirements. There is a trend of reinventing the wheel by going to in-house development without seeking help from other libraries that had gone through the same process or adopting cost-free international standard open source software. Hence, causing wastage of efforts, time and money (Asjad 2007; Mahmood 1996; Shafi-Ullah 2009; Shafique and Mahmood 2007).

Sufficient knowledge and training is required to carry out library automation activities but the majority of the librarians in Pakistan do not have such skills to run the automation projects. A large majority of the librarians know little about database management systems. Many professionals are even unable to use computers, Internet, e-mail and other related technologies. For that reasons, librarians are reluctant to participate in library automation activities. Consquently, the computer people of the organization take the opportunity to convince the authorities with their substandard software that do not fullfil the requirements of the libraries as the librarians have no participation in the development process that causes only wastage of time and resources (Haider 1998; Mahmood 1996; Ramzan 2004a; Riaz 1993). Other most commonly found problems are noncooperation from higher authorities, improper planning, non availability of training facilities, staff resistance, lack of consultancy firms, retrospective conversion and high cost of software (Ansari and Zia 2010; Idrees 1995; Ramzan 2004b).

The available literature also highlights valuable recommendations given by the experts of this field to overcome library software problems. Mahmood (1995) suggested that the library schools and library associations take the responsibility of selection and development of library software that can accommodate national and regional languages of Pakistan. In different studies, Asjad (2007), Idrees (1995),Yasmin and Bokhari (2007) emphasized on the acquisition of library software that fulfills the local needs of the Pakistani libraries along with the training of the professionals. 
In order to purchase and maintain hardware and software, Asjad (2007), Jabeen (2010), Ramzan and Singh (2009) recommended special budget for libraries. These studies also suggested training facilities for library staff to run library software efficiently. Shafique and Mahmood (2008) stressed educating the librarians about the importance and development of consortium through seminars and workshops. They also suggested that library schools, libray associations and software providers train librarians regarding the use of the software.

The Higher Education Commission (HEC) of Pakistan should follow the practices of advanced countries and establish consortium consisting of higher education institutions (HEIs) of Pakistan. The HEC should perform need analysis of the HEls and acquire a library management system to provide it to all libraries participaitng in the consortium. The HEC should also take the responsibility of providing training, paying annual support and maintenance charges (Ramzan 2004b; Shafi-Ullah 2009). Ramzan (2004b) recommended the development of a team of librarians and software engineers under the umbrella of a goverement body at national level, to be responsible for the development of library management system in meeting the local needs of the libraries. The team should also be responsible for technical support, upgrades and continous research and development of the software.

\section{OBJECTIVES AND METHOD}

The literature review has highlighted the gap in the identification of library software requirement and the library software selection criteria for libraries under the umbrella of Higher Education Institutions (HEls) of Pakistan. Therefore, the objective of this study is to explore experts' opinion regarding the current status of library software, problems faced and the needs of the libraries related to library software so that a need-based and sustainable solution for the automation of functions of the libraries may be suggested. The following research questions were set for this study:

a) What is the status of library software being used in higher education institutions of Pakistan?

b) What are the problems related to the implementation of the library software?

c) What are the indigenous needs of libraries regarding the library software?

d) What is the solution for the problems and indigenous needs of libraries regarding the library software?

This study was conducted using qualitative approach and focus groups were conducted in three big cities of Pakistan, i.e., Lahore, Islamabad and Karachi. For the selection of the participants for the study, the researchers consulted some experts from all over the country who were well known for library automation and had vast experience of working on library software. After consultation with the experts, a purposive selection of participants was made in this regard consisting of experts having experience of working on the library software. A discussion guide was also prepared on the basis of literature review and with the help of the experts. The sample for focus groups included librarians from higher education institutions, LIS educators with experience to teach library software, LIS experts having experience with designing and implementing library software and computer professionals having experience with library software. The participants were contacted through phone calls and after getting their consent, discussion guide with a cover letter was sent through emails. A total of three 
focus groups were set up; seven experts participated in the focus group conducted at Lahore (L1 to L7), nine at Islamabad (I1 to I9) and 10 at Karachi (K1 to K10).

Among these 26 expert participants, one was a professor of Library and Information Science having vast experience of teaching library automation courses and was also a consultant for developing software of a local vendor (K1). Two participants (L2 and I1) were chief librarians in well-reputed universities and both had doctorate and master degrees from foreign universities with their theses on library automation in Pakistan. Both participants had vast experience of consultancy on library automation and software. Another important participant (L3) was the secretary general of a national level group whose objectives were to promote automation activities in libraries of Pakistan. He was also developer of library software that was being used in many libraries of Pakistan and abroad. One participant (L4) was a software engineer and had been working on library software development from many years and was also doing customization of Koha, the open source library software. One participant (L5) was representative of internationally renowned proprietary software and providing support to different libraries in Pakistan. Five participants (L6, L7, 12, 13, 14) were librarians and also working as consultants for library automation in different organization funded by foreign agencies. One participant (K1) was a systems librarian of networks of libraries of an internationally renowned university having many campuses in all over the world. The remaining all participants were chief librarians/librarians of different universities having vast library automation experience with different library software including in-house developed, locally developed and off-the-shelf foreign software. Focus group discussions were taperecorded. The recordings were transcribed verbatim and matched with the notes taken by the researchers. The transcription was analyzed in detail and carefully reviewed. Detailed content analyses of all the transcribed pages were made and involved identification of the individual comments that were coded and grouped under similar concepts or themes.

\section{RESULTS AND DISCUSSION}

\section{Status of Library Software in Higher Education Institutions}

The experts participating in the focus groups shared their experiences and knowledge regarding the status of library software in the libraries of higher education institutions of Pakistan. They were of the view that the libraries did not have any proper software for automation in most cases, and that the libraries involved in automation activities were normally using two types of software, either "In-house developed software" or "Off-the-shelf imported software".

According to the participants, most of the libraries were using in-house developed software that was the result of customization of different database management systems. This nonstandard software was customarily developed using freely-available database management systems and even Microsoft Excel spreadsheet in some cases. They added that many departmental libraries of the University of the Punjab were using MLIMS which was a nonstandard software developed in-house. The experts cited examples of institutions that had developed a campus management system for the automation of their organizations involving different modules, the library module being one of them. One expert argued that "the situation is not too bad because the libraries using non-standard software maintained their 
data in some form that can be transferred to any standardized software when such software is arranged" (L3). However, all the experts had consensus on the need for provision of a standard library software that would meet the needs of libraries of the HEls of Pakistan.

The participants categorized standard library software as proprietary and open-source software. They stated that VTLS VIRTUA, a proprietary kind of software, was being used in three universities: the Lahore University of Management Sciences (LUMS), FC College University, Lahore, and Kohat University, Bannu, while other proprietary software such as Library World was being used at the National University of Textile (NTU) and departmental library of Business \& Information Technology, University of the Punjab, whereas the National College of Arts, Lahore, was using Alice for Windows. They added that Ghulam Ishaque Khan Institute of Engineering Sciences and Technology (GIKI) was using EOSI of Data Star but that was a DOS-based old version which had not been upgraded. Some libraries were using opensource software which they had adopted through their own efforts, with help from their IT departments in some cases. The participants also informed that Koha, an open-source library software, was more popular among libraries and had been adopted by libraries of the HITEC University and the International Islamic University.

The participants described the level of automation of libraries of HEls with different library software. They appraised the overall situation of library automation and believed that the progress of automation was not significant as the libraries had so far not automated all their functional requirements. In most cases the libraries had only implemented the cataloging modules while other modules such as acquisition and circulation were rarely implemented. The participants in general felt that the situation was not very different in the libraries that were using standard software either, since it was up to the capability of the libraries to what extent they utilized the standardized software. The participants also claimed that even the cataloging module was not fully implemented and one participant stated that "if a library has over 200,000 books and only cataloged 10,000 books with the software, then it cannot claim to have fully implemented the cataloging module" $(\mathrm{L} 3)$.

While evaluating the status of library software in HEls, participants believed that there were many evidences of individual efforts in the development of library software without any support, and only a few examples were available that represented joint efforts. They stated that the libraries had designed, or somehow got designed, library software to match their requirments without following any standards. Although this practice had helped in quicker automation process, it had also created problems due to non-standardization; for instance, the inability to share resources and perform Inter Library Loan (ILL) activities. Focus groups unianimously felt that the situation was different when public libraries were compared with those in the private sector, as the latter were in a better position in terms of the usability of library software. In the same way, the status of library software was much better in Lahore and Islamabad as compared to other cities in Pakistan. One expert mentioned that "there are not good stories of library software in public sectors' libraries but in private sector, librarians have to perform and have developed or got developed some applications to match their needs but these are not standardized software" (I3).

The experts participating in the focus groups felt that there was a scarcity of standardized library software that could meet the requirements of the libraries of HEls. Libraries that had made some progress in automating their processes were making efforts in isolation without 
benefiting from others' experiences or support. This is consistent with the findings of Mahmood (1996) and Shafique and Mahmood (2007). As pointed out earlier, according to the experts, the situation in private sector libraries was comparatively better than that in the public sector libraries as most of the latter were using non-standard library software that was the product of in-house development. The experts felt that although such software was helping libraries in automating their processes, it was also creating problems. (Note: the inhouse developed software was either the result of customization of available data management systems or of free software such as WINISIS).

The participants quoted, however, a few examples of implementation of standard library software, which were either proprietary or of the open-source type. Proprietary software used in some libraries included VIRTUA, Library World, EOSI of Data Star and Alice for Windows while Koha was the most popular open-source software that had been implemented in a few libraries. The experts also highlighted that although some libraries were automated with the in-house developed software, they had failed to fully implement this software, for example, most of the libraries had automated cataloging only, and the implementation of other modules such as acquisition and circulation was not very common. This was also true of the standardized software, whether proprietary or open-source, that contained all the standard modules required by any library.

\section{Problems Regarding Implementation of Library Software}

According to the focus groups, the available literature on library automation highlighted many problems in the current library automation of Pakistani libraries as some of their problems were similar to those mentioned in the literature. The participants confirmed that there was a scarcity of standard library software in Pakistan, whether off-the shelf, imported or locally developed software, that could meet the indigenous needs of libraries. They added that there was no study at the national level that could represent the current status of library software in libraries of HEls. They added that lack of proper documentation was another issue, for instance, no proper documentation was available to guide library automation standards in Pakistan. They felt that it was the responsibility of organizations such as the Higher Education Commission (HEC) and the Pakistan Library Association (PLA), but these organizations had not been effective in producing any results in this regard.

Other problems, emerged from the discussions, were the lack of capacity and awareness, and the limited vision of library professionals in Pakistan. The education sector had a very low budget, and libraries received a very small share of the financial resources, as such the libraries could not afford expensive software. Some experts among the participants were of the view that there was not an issue of funding because if library professionals had been mobilized and they had good networking, then they could have arranged enough funds. They said that most libraries had funds but it depended on their priorities how they spend the funds. As indicated by a participant: "They had different priorities because they preferred to spend heavy amounts on interior decoration and furniture but not on software" (L6). One expert mentioned another impeding factor, that library professionals in Pakistan "had failed to earn the confidence of their organizations because of their incompetency in new technologies due to which the heads of organizations normally preferred the opinion of IT departments over that of the library professionals for library automation" (L2).

Some participants also claimed that if there had been a proper vision, resources would have 
been made available. They felt that library professionals feared innovation and they were afraid of making new experiments. Howevere, one expert contradicted this opinion by saying that: "There have not been a lack of vision. The HEC National Digital Library Program is one of the big examples in this context. When the HEC provided the resources through the HEC National Digital Library Program, the professionals enthusiastically adopted it, got training to use it and became experts in digital library maintenance and running." (L3). He insisted that the big problem was funding. He admitted that "though the HEC has provided funding, it is limited to a small number of organizations. The example is the University of Engineering and Technology (UET) Lahore, to which the HEC has provided funding to the exclusion of other libraries"(L3). One expert expressed disappointment while disclosing the fact that "a golden opportunity has been missed by the professionals due to their internal conflicts during the regime of Pervez Musharraf when funds were available and a move for the acquisition of library software through the HEC had been initiated" (I5).

Another expert, who was a professional software engineer, was of the view that "the big issue is how to address the local needs" (L4). However, other expert participants contradicted this opinion and claimed that international software took care of the local needs of libraries as well by providing customized solutions.

Other issues highlighted by the participants were retrospective conversion, the existence of materials in the collections in the regional languages, lack of trained manpower, lack of vision and unavailability of infrastructure. Some of were the view that the availability of library software was not a big issue, while expressing the pleasure in the emergence of open-source software like Koha. They said that the problem was its customization and the fact that library professionals were not trained enough to carry out such customization; thus, due to their inability to customize and run the open-source software, the professionals were reluctant to adopt them.

The participants were of the view that the libraries were not given importance as compared to other departments of the institutions; there was not only an awareness issue among library professionals but also among the top management who did not have much vision about libraries. The experts felt that the top management did not realize the importance of software for the smooth running of library operations, but on the other hand, happily arranged standard software for other departments such as accounts and administration.

The expert participants lamented the fact that there was no IT policy in the automation of libraries and implementation of the appropriate library software, either at the government level or from the library professional bodies. The participants pointed out that there was no awareness among the library professionals in library automation and usually parent organizations assigned the task of software development to their IT departments. The experts emphasized that library professionals were normally not involved in such projects due to their ignorance, and on the other hand, IT professionals, being unaware of the domain information of the libraries, failed to fully address the needs of libraries in the software they made.

Another main problem highlighted by the expert participants was the current security situation of Pakistan that prevented well-reputed library systems vendors from visiting Pakistan for reasonable solutions of library automation. The experts said that lack of electricity, continuous load-shedding and unavailability of uninterruptible power supply (UPS) 
were also major problems, because professionals knew that without electricity their automation projects could not run.

Another factor identified by the experts was that library professionals and their professional bodies had poor knowledge about the acquisition of library software and all were working in isolation without sharing their experiences. One expert criticized this in this way: "there is no concept of blogging in Pakistan through which someone in the library software acquisition process can seek help from experienced professionals" (L7). The experts also said that the libraries that had been using any turnkey ILS did not encourage other libraries to use the same systems.

Participants also blamed library schools for not using any integrated library systems, and therefore, not providing practical training to the LIS students. After completion of their degree, the students do not have any practical working experience of integrated library systems, therefore, faced many problems in their professional life.

The participants suggested the following measures to resolve problems in implementing ILS in libraries:

a) A needs assessment of libraries should be carried out to identify actual requirements regarding library software so that needs-based software may be developed. It was also suggested by Shafique and Mahmood (2008).

b) The HEC should take responsibility of launching projects for automation of libraries of HEls and set up a standardized library system as a consortium similar to its National Digital Library Program, as also suggested by Shafi-Ullah (2009).

c) The HEC should provide a collaborative platform so that library professionals may discuss and share their problems as well as ideas with each other.

d) The library schools, professional library associations and volunteer groups should play their role in continuing professional education (CPE) of librarians. This was also recommended by Shafique and Mahmood (2008).

e) The library schools should revise their curriculum according to the emerging trends regarding ICTs, as also suggested by Shafi-Ullah (2009).

f) There is a dire need to highlight the importance of library software to the top management of HEls to make them realize that there should not be any library without computers and library software in future.

g) The HEC should grant a university charter to only those organizations that have implemented standardized software in their libraries.

h) There should be a standardized criteria for the selection of library software. Library professionals should have strong relations with their respective IT departments because they need additional support from them. It was also suggested by Iwe (2000).

\section{Indigenous Needs of Libraries Regarding Software}

The experts presented different opinions about the indigenous needs of libraries regarding software. They asserted that in most libraries the collections consisted of materials in different regional languages causing a hindrance in automation. They suggested that the software should be able to accommodate all regional languages and one participant was of the view that "it should also provide virtual keyboards for these languages on OPAC and WebOPAC". (L3). 
Other highlighted issues were related to acquisition and serials modules. The experts were of the view that there was a difference in the library acquisition process between Pakistan and other countries. Libraries abroad normally acquired materials directly from publishers, whereas in the case of Pakistan, libraries did not acquire material directly from publishers but from vendors. Therefore, in such a case, libraries could not send reminders for missing items to vendors. The experts further stated that there should be a currency conversion facility in the software as it would help in the library audit.

Only one expert completely contradicted the issue of indigenous needs by saying that "the local or indigenous needs are only a myth and just causing a hindrance in the implementation of library software in libraries" (L6). He commented that "when we buy something we should do some give and take and have the processes adapted according to the features available in the software". Another expert stated that "all international software cover internationally recognized languages as they are developed keeping in view the international market" (L5). He further remarked that "needs of the libraries of HEls varies from library to library and language is not an issue for all libraries".

According to the focus group participants, library users are now highly computer-literate and there has been a complete shift in their expectations for library systems. They emphasized that the software should be user-friendly and should focus on the needs of the library users since the users expected all library resources to be accessible on campus or off campus at their desktop and even on their mobile phones in order to reduce their library visits. They demanded the availability of virtual reference and visualized the OPAC as the next generation portal.

\section{Solutions for the Problems and Indigenous Needs}

\section{a) Modules Required for Automation}

While discussing the required modules, most of the expert participants recommended the availability of all standard modules in a library software. Some expressed their views that, as all the available modules were good enough to manage the traditional print collection of a library, a module was required for the management of electronic resources in addition to the standard modules. One expert claimed the existence of such a module for "the management of electronic resources that could also be integrated with the standard modules of the library software" (I3). The experts also stated that they could not find any single integrated library system in the market that could accommodate both print and electronic collections. They added that although some vendors provided software for print collection and different software for electronic collection, a single platform was still not available that accommodated both types of collections.

\section{b) Financial Support}

The expert participants highlighted three types of required funding: (a) Funding for development; (b) Funding for implementation; and (c) Funding for support. The experts in general felt that different funding agencies could be explored because both national and international funding agencies were available e.g., UNESCO could be approached as an international agency and the HEC was available as the national funding agency. The experts were of the view that only half of the required funds should be obtained from the funding agencies and the rest should be contributed by the HEls themselves as this practice would help 
in gaining the confidence of the funding agencies in the HEls and raise the chances of getting funds. Likewise, experts also suggested that the funds could be requested for the development and implementation of software, whereas the expenses of maintenance and support could be contributed by the HEls.

A few experts suggested that the adoption of open-source software and the customizing costs should be financed by the government through the HEC. They also stressed the forming of a consortium under the umbrella of the HEC that included HEls. They added that such a consortium should decide the adoption of open-source software or other technologies for the development of library software and fix the price limits for such software. One expert, who contradicted the suggestion regarding the involvement of the HEC, was of the view that: "If we do not want to resolve a problem then we pass it on to bodies like HEC, and that we should not look towards HEC or the government; HEls must come forward and take initiative to resolve their own problems" (12).

While arguing this issue other experts defended their statement regarding the involvement of the HEC saying that "a government body for supervision is required" (I3). They quoted the example of the National Digital Library Program initiated by the HEC that was running successfully and HEls were getting benefit from it. They felt that similar steps could be taken by the HEC which would help in reducing the cost and maintaining the standards.

\section{c) Development of the Library Software}

Most of the expert participants recommended the adoption of available library software with necessary customization instead of developing it from scratch. In line with the findings of Rafiq and Ameen (2009), the experts considered that open-source software was more suitable for the Pakistani environment as compared to off-the-shelf imported software. The experts reiterated the need for the formation of a consortium that would be responsible for selection of open-source software and get it customized according to the needs of the HEl libraries.

A few experts were against the in-house development of software and cited some failure cases in this regard. This was mainly due to dependence on a single person or group of persons who were involved in the development process and then left the organizations due to some reason; and this jeopardized the sustainability of the software. They said that this was not the case with off-the-shelf imported software, because there was normally an agreement for the support and maintenance of the software when it was acquired and libraries could get technical support on a single call for tension-free solutions.

Finally, all experts had a consensus on the formation of a consortium that should be supervised by a government body such as HEC. They quoted the example of INFLIBNET, a consortium model implemented in India that provided a solution for integrated library systems, digital libraries for participating libraries and also provided training to library staff. Therefore, similar model should be followed in Pakistan and a consortium comprising the libraries of HEls and supervised by HEC should be formed. The participants suggested that the consortium should arrange funds but the participating libraries should also contribute from their own resources.

\section{d) Technology Used}

Most expert participants agreed on the adoption of open-source tools for the development of 
library software that included open-source databases, web services, operating systems and programming languages.

\section{e) Distribution of Software}

Expert participants were of the view that the development should be carried out under the supervision of the proposed consortium under the umbrella of HEC, and this consortium should have the authority to distribute the software to the libraries of HEls. A few experts suggested that the development should be done under the supervision of this consortium but distribution rights should belong to the Pakistan Library Association (PLA).

\section{f) Data and Retrospective Conversion}

All experts agreed that the consortium should make arrangements for the data and retrospective conversion of the participating libraries. One expert suggested that "a knowledge base should be maintained that can archive all problems occurring in the data conversion process and their solutions for the future guidance of the professionals" ( L3).

\section{g) Training Required for Library Professionals}

There was a consensus among the experts about training of library professionals for smooth running of the software. They felt that the training relevant to library software should be made compulsory, and such training should be provided by the proposed consortium. The experts also recognized that it would not be possible for the consortium to provide training to each and every library professional of the participating libraries. Therefore, the consortium and professional associations should jointly prepare some master trainers who would volunteer to impart training to all library professionals. The experts also suggested that skilled library professionals should come forward and volunteer for such trainings.

\section{h) Pricing}

Participants believed that there should be a price for the software and that it should be determined module-wise. However, some experts were of the view that if the HEC provides funds then there should not be any price for the software, which could be distributed among the participating libraries gratis.

\section{i) Support and Maintenance}

Again the experts agreed that the consortium should be responsible for providing support, maintenance and new versions of the software to the participating libraries.

\section{j) Research and Development}

Because the experts agreed that the new version should be provided by the consortium they suggested that the research and development should also be the responsibility of the consortium, which could develop new versions of the software by incorporating into it the emerging technologies and needs of the libraries.

\section{k) Need for Systems Librarians}

All expert participants had a consensus on the recruitment of systems librarian for the smooth running of library software. 


\section{CONCLUSION AND RECOMMENDATIONS}

The experts participating in three focus groups shared their knowledge and experiences regarding the status of library software. The experts were of the view that there was scarcity of library software in the HEls of Pakistan and that most of the libraries that were in the process of automation were working in isolation without following any standards. They felt that only a few libraries were using standardized library software, and the level of automation was not presentable as most of the library automation was only limited to the cataloging process. The experts highlighted various problems regarding the implementation of the software including the non-availability of standard library software, regional language problems, lack of capacity, lack of awareness, and the narrow vision of library professionals, as well as the lack of funds and vision in the top management of HEls. The experts suggested that the HEC should take the responsibility for forming a consortium of the libraries of HEls so that standardized library software could be developed to fulfill the local needs of the libraries.

Based on the findings from the focus group discussions, the following recommendations are formulated:

a) The HEC should formulate a consortium consisting of the libraries of higher education institutions of Pakistan.

b) The consortium should be responsible for the development of library software keeping in view the indigenous needs of libraries.

c) The proposed software should be developed using internationally available open source library software.The consortium should decide about the selection of open source library software such as Koha and Evergreen. The library software should be developed using open source tools, for instance, open-source databases, web services, operating systems and programming languages.

d) The HEC should provide funds for the development of software. The software should be able to accommodate both print and electronic resources and provide single interface for the users to search both resource types, either from their desktop or from their mobiles. The software should be consisted of all standard modules that are normally available in all standard library software available in the international market.

e) The consortium should have rights to distribute the software among libraries. The consortium should provide retrospective conversion facility to libraries.

f) A knowledgebase should be maintained to archive problems faced by the libraries relevant to software and their solutions for further guidance of the professionals.

g) The consortium and professional bodies such as PLA should train some master trainers who provide training to the library professionals of higher education institutions.

h) The proposed software should be provided to the libraries free of cost but the libraries should contribute nominal amount in terms of support and maintenance charges.

i) The consortium should be responsible for the continuous research and development of the software and provide new versions of the software free of cost to libraries participating in the consortium.

j) The libraries should hire systems librarians for smooth running of the software. 


\section{ACKNOWLEDGEMENT}

This research received no specific grant from any funding agency in the public, commercial, or not-for-profit sectors.

\section{REFERENCES}

Ahmad, M. 1993. Library automation: Survey of computerized library services in federal area (Islamabad/Rawalpindi). In F. Mohammad (Ed.), Challenges in automating the library services (pp. 47-49). Peshawar: Department of Library \& Information Science, University of Peshawar.

Amekuedee, J.-O. 2005. An evaluation of library automation in some Ghanaian university libraries. Electronic Library, Vol. 23, no. 4: 442-452.

Ansari, M. N., and Zia, M. W. 2010. Automation of school libraries in Karachi. Library \& Information Science Journal, Vol. 41, no. 1: 9-41.

Asjad, R. 2007. The status of automation in the institutional libraries of University of the Punjab. Master thesis, University of the Punjab, Lahore.

Bills, L. 2000. Technical services and integrated library systems. Library Hi Tech, Vol. 18, no. 2: 144-150.

Fayen, E. G. 2010. Integrated library systems (ILS). Encyclopedia of Library and Information Sciences (3rd ed., pp. 2808-2819). London: Taylor \& Francis.

George, G. E. 2007. The impact of modern information technology in the Caribbean: Exploring the challenges for the technical services division. In C. Peltier-Davis \&S. Renwick (Eds.), Caribbean libraries in the 21st century : Changes, challenges, and choices (pp. 173-188). New Jersey: Information Today.

Haider, S. J. 1998. Library automation in Pakistan. Library Review, Vol. 30, 51-69

Idrees, H. 1995. A study of automation in libraries of Lahore. Master thesis, University of the Punjab.

Iwe, J. I. 2000. Automating library processes in the University of Calabar. Information Development, Vol. 16, no. 1: 29-33.

Jabeen, H. M. 2010. Continuing education for development of information technology in Pakistani libraries. Library \& Information Science Journal, Vol. 41, no. 3: 16-26.

Kinner, L., and Rigda, C. 2009. The integrated library system: From daring to dinosaur? Journal of Library Administration, Vol. 49, no. 4: 401 - 417.

Mahmood, K. 1995. Library software in Pakistan. Information Development, Vol. 11, no. 3: 165167

Mahmood, K. 1996. Status of library automation in Pakistan. Library Review, Vol. 45, no. 6: 3642.

Misra, V. N., and Phadke, D. N. 1995. Information technology and libraries. In D. C. Ojha (Ed.), Computer applications in library and information science (pp. 1-27). Jodhpur: Scientific Publishers.

Rafiq, M. and Ameen, K. 2009. Issues and lessons learned in open source software adoption in Pakistani libraries. The Electronic Library, Vol. 27, no. 4: 601-610.

Ramzan, M. 2004a. Effect of IT utilization and knowledge on librarians' IT attitudes. The Electronic Library, Vol. 22, no. 5: 440-447.

Ramzan, M. 2004b. Levels of information technology (IT) applications in Muslim world libraries. The Electronic Library, Vol. 22, no. 3: 274-280. 
Ramzan, M. and Singh, D. 2009. Status of information technology applications in Pakistani libraries. The Electronic Library, Vol. 27, no. 4: 573-587.

Riaz, B. A. 1993. Library automation problems in Pakistan. In F. Mohammad (Ed.), Challenges in automating the library services (pp. 27-34). Peshawar: Department of Library and Information Science, University of Peshawar.

Rubin, R. E. 1998. Foundations of library and information science. New York: Neal-Schuman.

Shafi-Ullah, F. 2009. Library automation initiatives in developing countries: Case studies of the public sector universities in Islamabad (Pakistan). Master thesis, Thames Valley University, London.

Shafique, F. and Mahmood, K. 2007. Librarians' opinions about library software: A survey of libraries in Lahore. Electronic Library, Vol. 25: 766-777.

Shafique, F., and Mahmood, K. 2008. Integrated library software: A survey of Lahore. Library Hi Tech News, Vol. 25, no. 6: 6-13.

Wang, Z. 2009. Integrated library system (ILS) challenges and opportunities: A survey of U.S. academic libraries with migration projects. The Journal of Academic Librarianship, Vol. 35, no. 3: 207-220.

Wijayaratne, A. 2005. Automation of library functions with special reference to circulation system adopted at the library of open university of Sri Lanka. Journal of the University Librarians Association of Sri Lanka, no. 9: 12-22.

Yasmin, N., and Bokhari, L. N. 2007. Status of automation in S\&T libraries of Pakistan. Paper presented at the PLA Golden Jubilee International Conference on Emerging Paradigm in Librarianship: A Call for Innovation, Lahore. 